\title{
Detection and difference analysis of the enzyme activity of colloidal gold nanoparticles with negatively charged surfaces prepared by different reducing agents
}

\section{Junjun Cao}

Shihezi University

Jie Zhang

Shihezi University

Ning Yuan

Shihezi University

Yixiao Sun

Shihezi university

\section{Zhihua Xu}

Shihezi University

Feng Shi ( $\square$ shifeng2314@yeah.net)

shihezi university

\section{Research article}

Keywords: colloidal gold, negative charge, nanoenzyme

Posted Date: May 7th, 2021

DOl: https://doi.org/10.21203/rs.3.rs-496828/v1

License: (c) (i) This work is licensed under a Creative Commons Attribution 4.0 International License.

Read Full License 


\title{
Detection and difference analysis of the enzyme activity of colloidal gold nanoparticles with negatively charged surfaces prepared by different reducing agents
}

\author{
Junjun $\mathrm{Cao}^{1}$, Jie Zhang ${ }^{1}$, Ning Yuan ${ }^{1}$, Yixiao $\mathrm{Sun}^{1}$, Zhihua $\mathrm{Xu}^{1}$, Feng Shi ${ }^{1 *}$ \\ ${ }^{1}$ College of Life Sciences, Shihezi University, Xin Jiang, Shihezi 832000, China \\ E-mail address: shifeng2314@yeah.net.
}

Abstract : Research on the activity of nanoenzymes has always been a focus of nanomaterials. In this study, several reducing agents with different structures were used to prepare colloidal gold with a negative charge and similar size by controlling the temperature and $\mathrm{pH}$. The affinity analysis of the substrate $\mathrm{H}_{2} \mathrm{O}_{2}$ and TMB showed that the activity of colloidal gold nanoenzymes prepared by different reducing agents was in the order of $\mathrm{Cc}, \mathrm{Hq}, \mathrm{Rs}, \mathrm{Vc}, \mathrm{Ga}, \mathrm{Sc}, \mathrm{Sm}, \mathrm{St}$. The rule is that the enzyme activity of colloidal gold reduced by benzene ring is higher than that of colloidal gold enzyme reduced by linear chain. Finally, we discussed the activity of colloidal gold peroxidase from the number and position of isomers and functional groups, and demonstrated that the nanoenzyme activity affected the surface activity of colloidal gold, the elimination of hydroxyl radical and TMB binding efficiency.

Keywords: colloidal gold; negative charge; nanoenzyme;

Introduction

Natural enzymes, such as proteins, RNAs, or their complexes, are widely used in the fields of disease diagnosis, clinical treatment, biosensing, and environmental protection due to their high catalytic efficiency and selectivity [1-4]. However, under extreme conditions (strong acid, strong alkali, high temperature, etc.), these enzymes are easily inactivated and have high extraction costs and low yields, making them difficult to use in large-scale industrial production [5].Therefore, it is desirable to find natural enzyme substitutes with strong catalytic activities and stabilities [6,7]. In 2007, Yan et al. discovered for the first time that ferrous oxide magnetic nanoparticles $\left(\mathrm{Fe}_{3} \mathrm{O}_{4} \mathrm{MNPs}\right)$ possess intrinsic peroxidase-like activity [8]. The enzymatic properties of nanomaterials were systematically studied from the perspective of enzymology, and corresponding determination standards were established, which were used as substitutes for enzymes [9]. In 2013, Wei et al defined such nanomaterial mimetic enzymes as nanoenzymes. Nanoenzymes are artificial mimetic enzymes with catalytic functions and unique physicochemical properties [10]. At present, most metal oxides, noble metals, and carbon-based nanomaterials are found to have enzymatic activity, and can simultaneously exhibit the activity of one or more enzymes, such as oxidase, superoxide enzyme, catalase [11-15]. Their catalytic reaction is similar to that of natural enzymes, which not only conforms to the kinetic curve of Michaelis-Menten equation but also is affected by temperature, substrate concentration, and $\mathrm{pH}[16]$. 
The catalytic reaction of nanoenzymes occurs on the surface of nanomaterials, which is essentially the process of surface electron transfer; the size effects and surface active sites of these materials are key factors that affect the catalytic activity [17-20]. The kinetic analysis of enzyme reaction shows that the surface modification of nano-mimic enzyme can change its affinity to the substrate, thus affecting its catalytic performance $[21,22]$. Therefore, the size and surface modification of nanoenzymes have become an important mean of regulate the activity of nanoenzymes and to provide a new route for the further research and application of nanoenzymes.

As a type of nanomaterials, colloidal gold have also been widely studied in the field of nanoenzyme due to its unique optical properties. Li et al. found that colloidal gold can exhibit the activity of oxidase [23]. Luo et al. speculated that the reaction followed the Eley-Rideal mechanism [24]. In addition, JV et al. explored whether colloidal gold have the characteristics of intrinsic mimic peroxidase and applied them to glucose detection and studied the difference in peroxidase activity between gold nanoparticles modified by different surface charges and bare gold nanoparticles, and finally found that the peroxidase activity of bare gold nanoparticles was the highest through a series of characterization data [25].

In this study, reductants with obvious structural differences were used to prepare colloidal gold with similar particle size and the enzyme activity was detected. Through the optimization of the morphology and particle size of the colloidal gold, the characterization of a series of data, and the detection of enzyme activity, it was found that the enzyme activity of the enzyme activity of colloidal gold reduced by benzene ring was higher than that of colloidal gold enzyme reduced by linear chain. The above experimental results verify the differences in nanoenzyme activities with different surface modifications and provide a theoretical basis for the in-depth study and application of nanoenzyme surface modification.

\subsection{Experiment methods:}

\subsubsection{Preparation of colloidal gold:}

To avoid affecting the accuracy of the experimental results, it is necessary to prepare colloidal gold by reduction without any stabilizer. Certain concentrations of the reducing agent, $\mathrm{pH}$ regulator and chloroauric acid solution were added in a certain proportion and order, and nanoparticles with similar particle size and morphology were prepared by controlling the reaction conditions [26]. The specific proportioning methods are shown in Table1.

Table1: Proportion of reagents for preparing colloidal gold

\begin{tabular}{|c|c|c|c|c|c|c|}
\hline Reducing agent concentration & $\mathrm{ddWH}_{2} \mathrm{O}$ & $\mathrm{HAucl}_{4}(1 \%)$ & $\mathrm{NaOH}(0.1 \mathrm{M})$ & $\mathrm{K}_{2} \mathrm{CO}_{3}(0.1 \mathrm{M})$ & $\operatorname{HCL}(0.1 \mathrm{M})$ & Reaction conditions \\
\hline$\Delta 72.7 \mu \mathrm{L} \mathrm{Hq}(30 \mathrm{mM})$ & $\bullet 9.696 \mathrm{~mL}$ & $\mathbf{m} 81.6 \mu \mathrm{L}$ & $\star 150 \mu \mathrm{L}$ & & & $50^{\circ} \mathrm{C}$ Stir \\
\hline
\end{tabular}




\begin{tabular}{|c|c|c|c|c|c|c|}
\hline$\Delta 100 \mathrm{ul} \mathrm{Cc}(30 \mathrm{mM})$ & $\bullet 9.62 \mathrm{~mL}$ & - $100 \mu \mathrm{L}$ & & $\star 100 \mu \mathrm{L}$ & & $50^{\circ} \mathrm{C}$ Stir \\
\hline $\boldsymbol{\Delta} 60 \mu \mathrm{L}$ Rs $(1 \%)$ & $\bullet 9.74 \mathrm{~mL}$ & - $100 \mu \mathrm{L}$ & & $\star 20 \mu \mathrm{L}$ & & Room temperature \\
\hline$\Delta 20 \mu \mathrm{L} \mathrm{Ga}(1 \%)$ & $\bullet 9.73 \mathrm{~mL}$ & 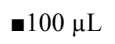 & $\star 150 \mu \mathrm{L}$ & & & Room temperature \\
\hline$\Delta 400 \mu \mathrm{L} \mathrm{Vc}\left(1.98 \times 10^{-3} \mathrm{M}\right)$ & $\bullet 9.52 \mathrm{~mL}$ & $\mathbf{\square} 100 \mu \mathrm{L}$ & & & $\star 100 \mu \mathrm{L}$ & $0^{\circ} \mathrm{C}$ Stir \\
\hline $\boldsymbol{\Delta} 100 \mu \mathrm{L} \mathrm{St}(1 \%)$ & $\bullet 9.72 \mathrm{~mL}$ & $=100 \mu \mathrm{L}$ & $\star 100 \mu \mathrm{L}$ & & & $50^{\circ} \mathrm{C}$ Stir \\
\hline - $100 \mu \mathrm{L} \mathrm{Dm}(2 \%)$ & $\bullet 9.8 \mathrm{~mL}$ & $\star 100 \mu \mathrm{L}$ & & & & Boil and stir \\
\hline$\square 100 \mu \mathrm{L} \mathrm{Sc}(2 \%)$ & $\bullet 9.8 \mathrm{~mL}$ & $\star 100 \mu \mathrm{L}$ & & & & Boil and stir \\
\hline
\end{tabular}

Note (addition order of reagents

1.2.2 Nano-enzyme activity verification

First, the activity of peroxidase-mimicking enzymes was preliminarily verified. It is generally believed that peroxidase-mimicking enzymes can catalyse the decomposition of $\mathrm{H}_{2} \mathrm{O}_{2}$ to produce free radicals and chemically react with a certain chromogenic substrate. In this study, TMB was used as the chromogenic substrate, and its oxidation product has an absorption peak at $652 \mathrm{~nm}$. The activity of the peroxidase-mimicking enzyme was preliminarily verified according to the change of absorbance. The enzyme activity was measure after confirming that it has peroxidase activity, and a(IU $\left.\cdot \mathrm{mg}^{-1}\right)$ was calculated.

Table 2: Nano-enzyme activity determination verification

\begin{tabular}{ccccc} 
Reactant & NaAc-HAc buffer $(\mathrm{mL})$ & Nanozyme $(\mathrm{mL})$ & $\mathrm{TMB}(\mu \mathrm{L})$ & $\mathrm{H}_{2} \mathrm{O}_{2}(\mu \mathrm{L})$ \\
Vial number 1 & 2 & 1.2 & 40 & 363.7 \\
Vial 2 & 2.364 & 1.2 & 40 & 0 \\
Vial 3 & 3.2 & 0 & 40 & 363.7 \\
\hline
\end{tabular}

1.2.3 Nanoenzyme activity determination and catalytic kinetics research

Different nanoenzyme solutions $(1.2 \mathrm{ml})$ were added into vials containing $2 \mathrm{ml}$ of a $0.2 \mathrm{M} \mathrm{NaAc}-\mathrm{HAc}$ buffer $(\mathrm{pH}=3.6)$; Forty microliters of TMB solution $\left(10 \mathrm{mg} \cdot \mathrm{mL}^{-1}\right)$ was added into the vial and mixed. In addition to the above samples prepared, prepare a sample without adding $\mathrm{H}_{2} \mathrm{O}_{2}$ as a blank; the reaction is carried out in the dark at $35^{\circ} \mathrm{C}$, and the absorbance at $652 \mathrm{~nm}$ is measured every $20 \mathrm{~s}$; the relationship between the absorbance at $652 \mathrm{~nm}$ and the reaction time is plotted to obtain the reaction -Time curve.

The following formula was used to calculate a nanozyme $\left(\mathrm{IU} \cdot \mathrm{mg}^{-1}\right)$ [27]:

$$
\begin{gathered}
\mathrm{b}_{\text {nanozyme }}=\mathrm{V} /(\varepsilon \times 1) \times \Delta \mathrm{A} / \Delta \mathrm{t} \\
\mathrm{a}_{\text {nanozyme }}=\mathrm{b}_{\text {nanozyme }} /[\mathrm{m}]
\end{gathered}
$$


By changing the concentration of the substrate $\mathrm{H}_{2} \mathrm{O}_{2}$ within a certain concentration range, the enzyme kinetics of the nanozyme was evaluated by the steady-state kinetic method. TMB was oxidized via the oxygen produced by catalytic decomposition to undergo a colour chromogenic reaction. As the concentration of the substrate increases, the reaction rate increases linearly and then tends to be saturated at a high concentration. This finding conforms to a typical Michaelis-Menten. The Michaelis curve was fitted with substrate concentration and initial catalytic velocity as the horizontal and vertical coordinates, respectively. Then, using the double reciprocal method, the Michaelis equation $\mathrm{V}=\mathrm{V}_{\max } \times[\mathrm{S}] /\left(\mathrm{K}_{\mathrm{m}}+[\mathrm{S}]\right)$ was constructed to calculate the reaction kinetic parameters. $\mathrm{K}_{\mathrm{m}}$ is the Michaelis constant, $\mathrm{V}$ is the initial rate of the reaction, and $[\mathrm{S}]$ is the concentration of substrate. The Michaelis constant is a measure of the binding ability of the enzyme to the substrate. The smaller the Km value is, the stronger the binding capacity to substrate, the greater the $\mathrm{Km}$ value and the weaker the affinity.

2 Results and discussion

\subsection{Optimization of nanoparticles}

Due to the requirements of experimental research, spherical gold nanoparticles with identical size were synthetized. The characterization outcomes demonstrated that the colloidal gold, produced with the methods in the relevant literature [28-32], have different size and various morphologies, except for some linear chain organic acids (tartaric acid, malic acid, citric acid) and Catechol. Resorcinol cannot be rapid oxidative self-conversion into their quinone forms because of the lack of electronic resonance in aromatic nucleus; therefore, its slow reduction process, unlike other Hydroxylphenols, causes the colloidal gold to exhibit irregular diameters. The negative and positive charges of Hydroxylphenols, whose magnitudes also affect the ability to gain and lose electrons, are mainly distributed on the oxygen and aromatic ring. Compared with other hydroquinones, 1,4-hydroquinone has the strongest electron gain and loss ability. The colloidal gold fabricated using pyrogallic acid by reducing the corresponding metal ions $\left(\mathrm{Au}^{3+}\right)$ are affected by the quantity and position of their Hydroxyphenols, which makes their charge distribution uneven and ultimately leads to the uneven particle size. The formation of colloidal golds mediated by ascorbic acid occurs through releasing protons and electrons in an acidic medium, and the freed electrons eventually reduce $\mathrm{Au}$ (III) ions into colloidal golds, which are then covered by dehydroascorbic acid (DHAA) [33]. Clearly, the four alcoholic hydroxyl groups contained by nanoparticles are extremely reductive, as observed by the structure of the ascorbic acid, which ultimately results in the inhomogeneity of the colloidal gold sizes caused by the rapid reaction. In summary, there are two feasible main options to acquire colloidal golds with uniform particle size and spherical shape. The first is to add a stabilizer during the preparation process, and the second is to adjust the temperature and $\mathrm{pH}$ by altering the forms of the reducing agent and reaction rate. We 
eventually chose the second option owing to realities. The results shown in Table 1 are the specific optimization methods.

\subsection{Characterization of Nanoenzymes}

It is generally accepted that both the temperature and $\mathrm{pH}$ or enzyme concentration have a serious influence on enzyme activity. On the basis of the experiment carried out at room temperature, with a $\mathrm{pH} 3.6$, it can easily be discovered that the OD values of all kinds of colloidal gold are similar UV-vis spectroscopy (Figure 1), the results show that the concentrations of colloidal gold are extremely similar, which eliminates the impact of enzyme concentration.

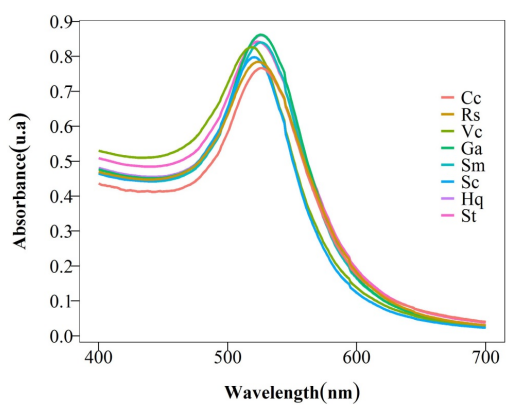

Figure 1: Visible light (400-700 $\mathrm{nm})$ absorption spectra of colloidal gold $(\lambda / \mathrm{nm})$

On the other hand, the size and surface modification of colloidal gold have a significant impact on their activity from the perspective of nanomaterials, illustrating that it is vital to fabricate colloidal gold with analogical particle sizes. As shown in Table 1, the concentration and dosage of various reducing agents are different in that the agents demonstrate a large structural difference. First, it can be concluded from the maximum absorption peak of the UV-vis spectroscopy finding that there is little difference between nanoparticle size prepared by different reducing agents (Figure 1). The zeta potential shows that the surface charge of all colloidal gold is negative. Transmission electron microscopy (TEM) images also intuitively reflect this result (Figure 2).
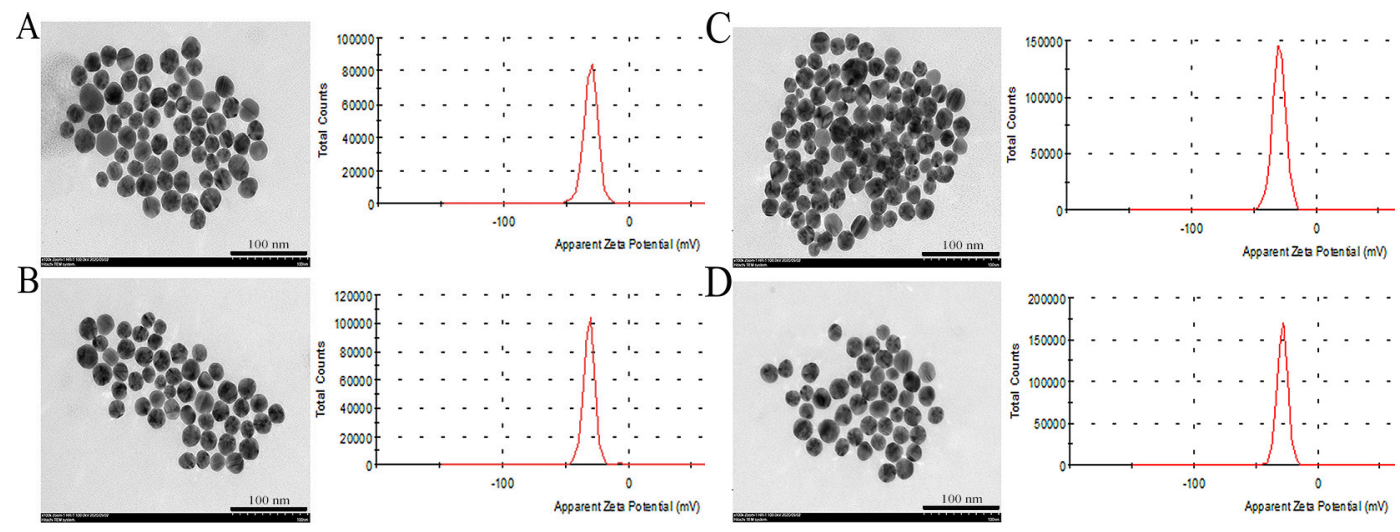

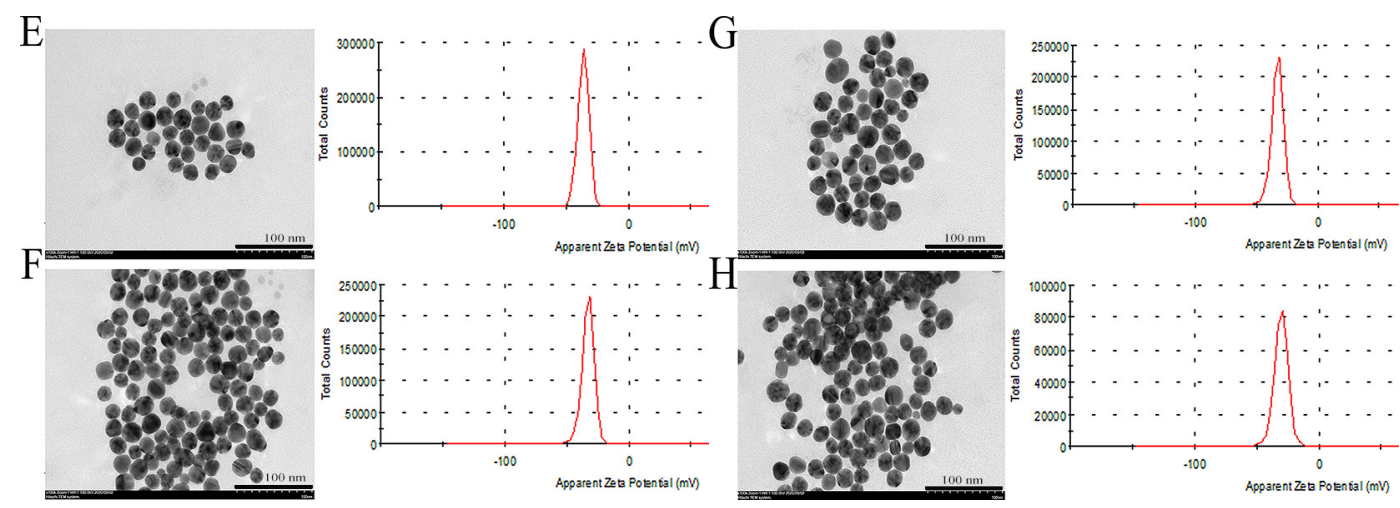

Figure 2: The particle size distribution, TEM and zeta potential of colloidal gold prepared by reduction with $\mathrm{Cc}(\mathrm{A}), \mathrm{Hq}(\mathrm{B}), \mathrm{Rs}(\mathrm{C}), \mathrm{Vc}(\mathrm{D}), \mathrm{Ga}(\mathrm{E}), \mathrm{Sc}(\mathrm{F}), \mathrm{Sm}(\mathrm{G})$ and $\mathrm{St}(\mathrm{H})$.

\subsection{Nanoenzymes activity verification}

The activity of mimic enzyme was initially verified by virtue of the colour development reaction, and its catalytic ability was determined, as shown in Figure 3.
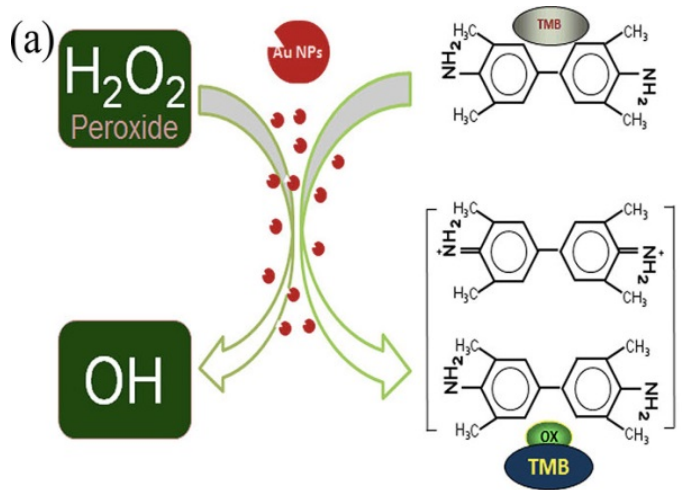

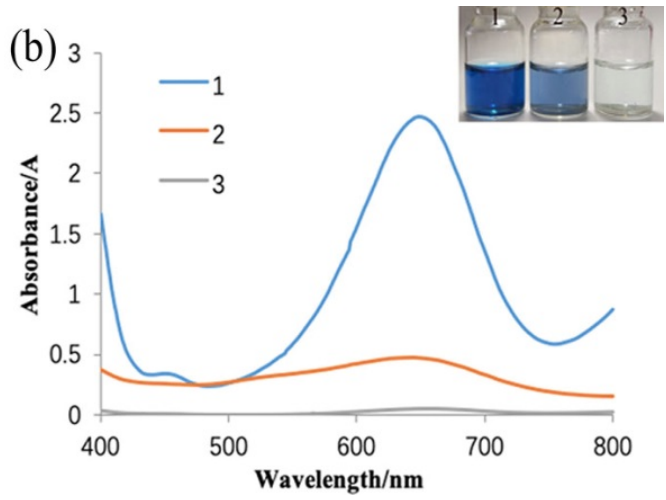

Figure 3 : (a) Mechanism of peroxidase activity of the colloid gold (b)UV spectrogram and photo of nanoenzyme activity verification

The results of the activities of eight prepared nanozymes indicated that their catalytic effects were similar. Taking hydroquinone as a reducing agent as an example, as shown in Figure 3b, the clear solution in the No.1 bottle containing both nanoenzymes, TMB and $\mathrm{H}_{2} \mathrm{O}_{2}$, gradually turns blue, and the product has a strong absorption peak at $652 \mathrm{~nm}$ which is determined to be the absorption peak of TMB oxidation. This is due to $\mathrm{H}_{2} \mathrm{O}_{2}$ decomposed after being catalyzed by nanoenzymes to produce a large amount of $\mathrm{O}^{2-}$ in the system, which oxidizes TMB to cause a colour development reaction so that it appears blue (Figure 3a). A slightly blue colour appeared in the solution of the second bottle containing nanoenzymes and TMB, and product also has a faint peak at $652 \mathrm{~nm}$ which is judged to be absorption peak of partial TMB oxidized by a small quantity of oxygen-containing substances adsorbed on the surface of nanoenzymes. On the basis of no-change in bottle 3 containing TMB and $\mathrm{H}_{2} \mathrm{O}_{2}, \mathrm{H}_{2} \mathrm{O}_{2}$ was not decomposed, and TMB was not oxidized when nanoenzymes were added to system. Conclusions: Nanoenzymes possess peroxidase catalytic activity. For the sake of unambiguous differences between 
nanoenzymes fabricated by various reducing agents, the enzyme activity and enzymatic reaction kinetics were explored.

2.3 Study on activity determination and catalytic kinetics of nanoenzyme

2.3.1 Research on the most suitable conditions for nanoenzyme activity

Taking the preparation of colloidal gold by Sc reduction as an example, Through orthogonal design on different temperature and $\mathrm{pH}$ conditions, the optimal temperature and $\mathrm{pH}$ conditions are shown in the following Figure 4: Clearly, when $\mathrm{pH}$ is 3.6 and temperature is $40^{\circ} \mathrm{C}$, the $\mathrm{OD}$ value $(2.91)$ is the highest, which reflects the highest activity of nanoenzyme.

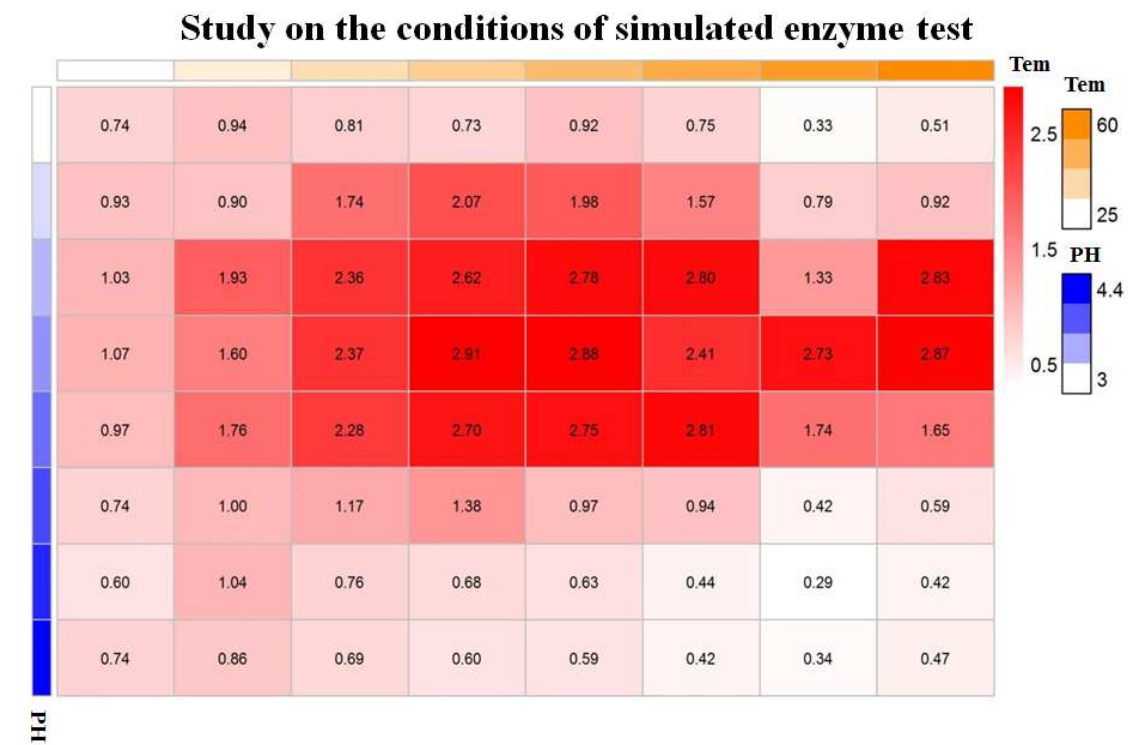

Figure 4: Orthogonal analysis of $\mathrm{pH}$ and temperature of colloidal gold prepared by Sc reduction method

\subsubsection{Determination of nanoenzyme activity}

It is well known that the peroxidase-like activity of colloidal gold results from their own. Before use, the prepared colloidal gold was centrifuged and then redispersed with ultrapure water to confirm the accuracy of the experiment and eliminate the influence of other impurities. $\mathrm{H}_{2} \mathrm{O}_{2}$ is decomposed into double $\mathrm{HO}^{*}$ radicals, which are adsorbed on the surface of AuNPs and stabilized by AuNPs through the interaction of partial electron exchange [34]. Finally, the catalytic performance of AuNPs was improved. In this experiment, the effects of reductants with different chemical structures on the properties of the prepared mimic enzymes were explored by investigating their enzyme activity and catalytic reaction kinetics of the mimic enzymes. According to the standard method provided by yan [27], the initial reaction rate under the condition of substrate saturation was selected as the standard to evaluate the enzyme activity. The change rate of absorbance with time is converted into that of concentration with time according to lambert-beer law. It is obvious that the activities of these eight 
enzymes are in the following sequence, namely, Cc, Hq, Rs, Vc, Ga, Sc, Sm and St from high to low (Figure 7). The control variable method was used to analyse whether the difference of colloidal gold surface modification leads to the difference in the affinity with the substrate. The affinity of the enzyme to the two substrates, $\mathrm{H}_{2} \mathrm{O}_{2}$ and TMB, was compared. From the $\mathrm{Km}$ value, it is not difficult to find that when the substrate is $\mathrm{H}_{2} \mathrm{O}_{2}$, the $\mathrm{Km}$ value is in the order of Sm, St, Sc, Vc, Rs, Hq, Cc and Ga (Figure 5). It is not difficult to find that the affinity of the mimic enzyme for the substrate has an almost a linearly positive correlation with the reducibility of the reductant, and the stronger the reducibility of the simulated enzyme is, the greater the affinity of the mimic enzyme for the substrate. It can be seen from table 3 that the affinity of the mimic enzyme modified by benzene ring is strongest, and the affinity of the mimic enzyme modified by $\mathrm{Vc}$ is stronger than that of the mimic enzyme modified by linear chain. The surface properties of AuNPs will change as well. By affecting the absorption of $\mathrm{H}_{2} \mathrm{O}_{2}$, the electron transfer processes mediated by particles are different. The stronger the reducibility of the reductants is, the easier it is for the reductants to bind to the colloidal gold surface and the easier it is for charge transfer occur, making the colloidal gold surface more active and faciliating $\mathrm{H}_{2} \mathrm{O}_{2}$ adsorption on the colloidal gold surface to form $\mathrm{HO}^{`}$ radicals [35]. The $\mathrm{Km}$ value magnitudes, when the substrate is TMB are in the following order: Hq, Rs, Cc, Ga, Vc, Sc, St, Sm (Table 4). The research shows that the activity of colloidal gold peroxidase was positively correlated with the affinity of the substrate hydrogen peroxide [1], From the Table 5, the colloidal gold peroxidase activity modified by eight different reducing agents is in order: Cc, Hq, Rs, Vc, Ga, Sc, Sm, St(from high to low).
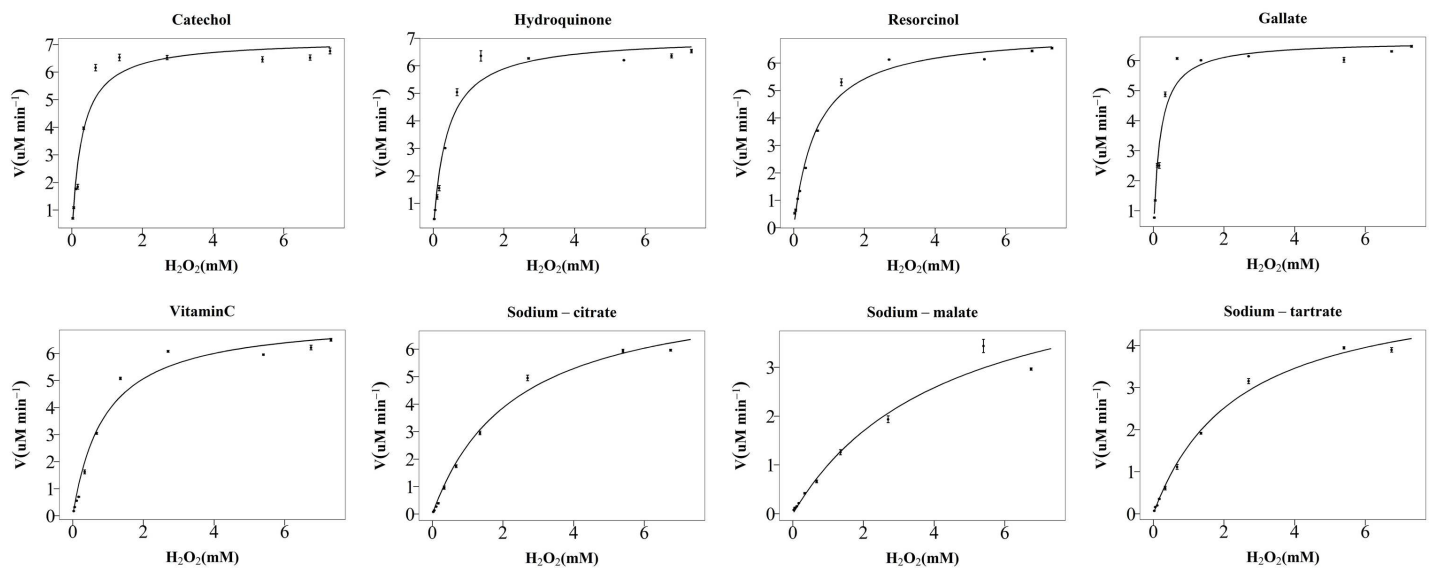

Figure 5: Michaelis-Menten curves for nanozymes prepared with eight different reducing agents, such as Cc, Hq, Rs, Vc, Ga, Sc, Sm and St. The concentration of TMB used was $1 \%$, and the $\mathrm{H}_{2} \mathrm{O}_{2}$ concentration varied from 0 to nearly $30 \%$. Error bars shown represent the s.e. derived from three independent experiments. 
Table 3: $\mathrm{K}_{\mathrm{m}}$ and $\mathrm{V}_{\max }$ with $\mathrm{H}_{2} \mathrm{O}_{2}$ as substrate

\begin{tabular}{lcccccccc}
\hline Type of reducing agent & $\mathrm{Cc}$ & $\mathrm{Hq}$ & $\mathrm{Rs}$ & $\mathrm{Ga}$ & $\mathrm{Vc}$ & $\mathrm{Sc}$ & $\mathrm{Sm}$ & $\mathrm{St}$ \\
\hline $\mathrm{K}_{\mathrm{m}}(\mathrm{mM})$ & 0.249 & 0.497 & 0.378 & 0.226 & 0.849 & 1.634 & 2.75 & 2.382 \\
$\mathrm{~V}_{\max }$ & 6.596 & 6.057 & 6.12 & 5.385 & 6.897 & 4.228 & 3.785 & 6.369 \\
\hline
\end{tabular}

Note: $\mathrm{K}_{\mathrm{m}}$ is the Michaelis constant, $\mathrm{V}_{\max }$ is the maximal reaction velocity
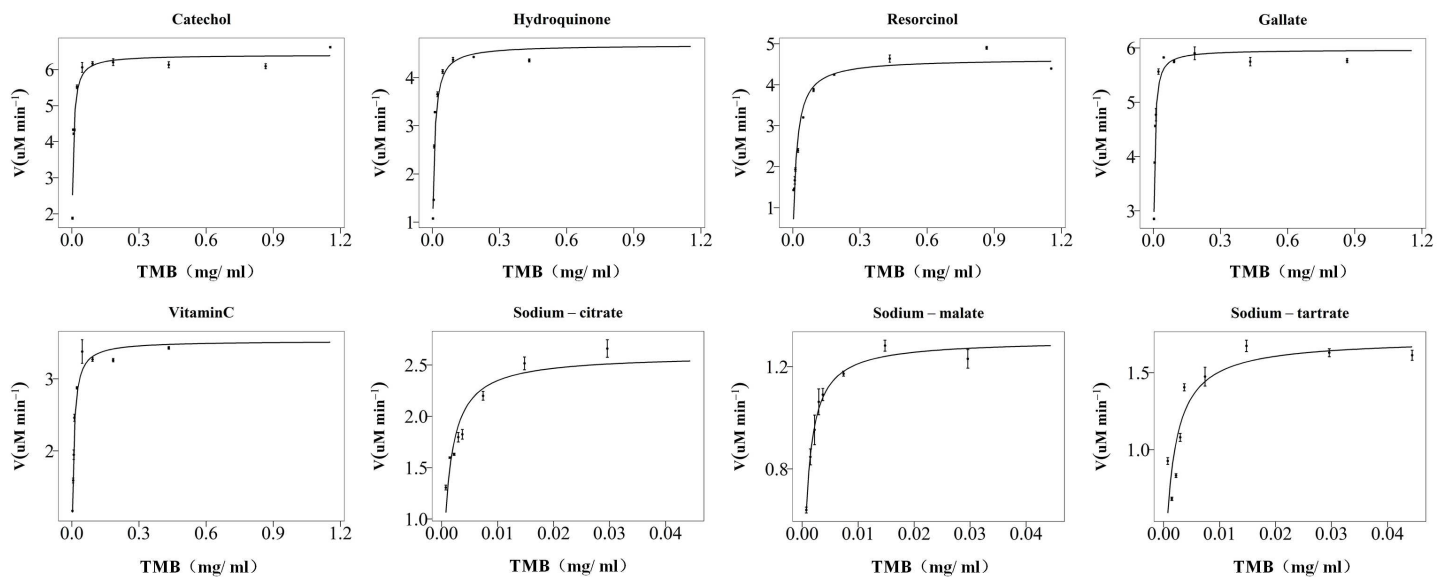

Figure 6: Michaelis-Menten curves for nanozymes prepared with eight different reducing agents, such as $\mathrm{Cc}, \mathrm{Hq}, \mathrm{Rs}, \mathrm{Vc}, \mathrm{Ga}, \mathrm{Sc}, \mathrm{Sm}$ and St. The concentration of $\mathrm{H}_{2} \mathrm{O}_{2}$ used was $30 \%$, and the TMB concentration varied from 0 to nearly $1 \%$. Error bars shown represent the s.e. derived from three independent experiments.

Table 4: $\mathrm{K}_{\mathrm{m}}$ and $\mathrm{V}_{\max }$ with TMB as substrate

\begin{tabular}{lllllllll}
\hline Type of reducing agent & $\mathrm{Cc}$ & $\mathrm{Hq}$ & $\mathrm{Rs}$ & $\mathrm{Vc}$ & $\mathrm{Ga}$ & $\mathrm{Sc}$ & $\mathrm{Sm}$ & $\mathrm{St}$ \\
\hline $\mathrm{K}_{\mathrm{m}}(\mathrm{mg} / \mathrm{ml})$ & 0.0074 & 0.0153 & 0.0105 & 0.003 & 0.0059 & 0.0026 & 0.0008 & 0.0016 \\
$\mathrm{~V}_{\max }$ & 6.689 & 4.496 & 5.01 & 6.039 & 3.495 & 1.866 & 1.306 & 2.729 \\
\hline
\end{tabular}

Note: $\mathrm{Km}$ is the Michaelis constant, $\mathrm{V}_{\max }$ is the maximal reaction velocity

Table 5: The results of enzyme activity measurement

\begin{tabular}{ccccccccc}
\hline Type of reducing agent & $\mathrm{Cc}$ & $\mathrm{Hq}$ & $\mathrm{Rs}$ & $\mathrm{Vc}$ & $\mathrm{Ga}$ & $\mathrm{Sc}$ & $\mathrm{Sm}$ & $\mathrm{St}$ \\
\hline $\begin{array}{c}\text { Total } \\
\text { The amount nanozyme }\end{array}$ & & & & & $4 \mathrm{ml}$ & & & \\
added & & & & $500 \mu \mathrm{L}$ & & & \\
nanozyme concentration & & & & & & & & \\
$\left(\mathrm{mg} \cdot \mathrm{ml}^{-1}\right)$ & 0.0816 & 0.1 & 0.1 & 0.1 & 0.1 & 0.1 & 0.1 & 0.1 \\
$\mathrm{~b}(\mathrm{IU})$ & 0.058 & 0.023 & 0.018 & 0.012 & 0.011 & 0.004 & 0.0023 & 0.0022 \\
$\mathrm{a}\left(\mathrm{IU} \cdot \mathrm{mg}^{-1}\right)$ & 1.415 & 0.464 & 0.378 & 0.242 & 0.219 & 0.084 & 0.047 & 0.044 \\
\hline
\end{tabular}


However, why is there a difference in the end? (Figure 6) First, due to the resonance between the nonbonding PZ orbital of the phenolic hydroxyl oxygen atom and the $\pi$-bonding orbital of the benzene ring, the phenolic hydroxyl oxygen has a higher electron density [36], And it was bound to the surface of colloidal gold, which greatly increased its reactivity. Second, as a radical scavenger, Vc competed with TMB, which resulted in the radicals $\mathrm{HO}^{*}$ not completely reacting with TMB. Finally, colloidal gold capped with carboxyl groups (citrate, etc.) tend to electrostatically attract the amino groups of TMB, moreover, the carboxyl moieties of linear chain organic acids are more easily adsorbed on the surface of colloidal gold, making the colloidal gold surface exposed moieties relatively less, leading to the relative difficulty of $\mathrm{H}_{2} \mathrm{O}_{2}$ adsorption on the colloidal gold surface. Compared with nanoparticles modified by other structures, its affinity with TMB is greater. The results showed that the affinity of the nanoenzyme prepared by reduction of phenolic compounds was higher than that of the nanoenzyme reduced by linear chain organic acids.

\section{Peroxidase-like activity}

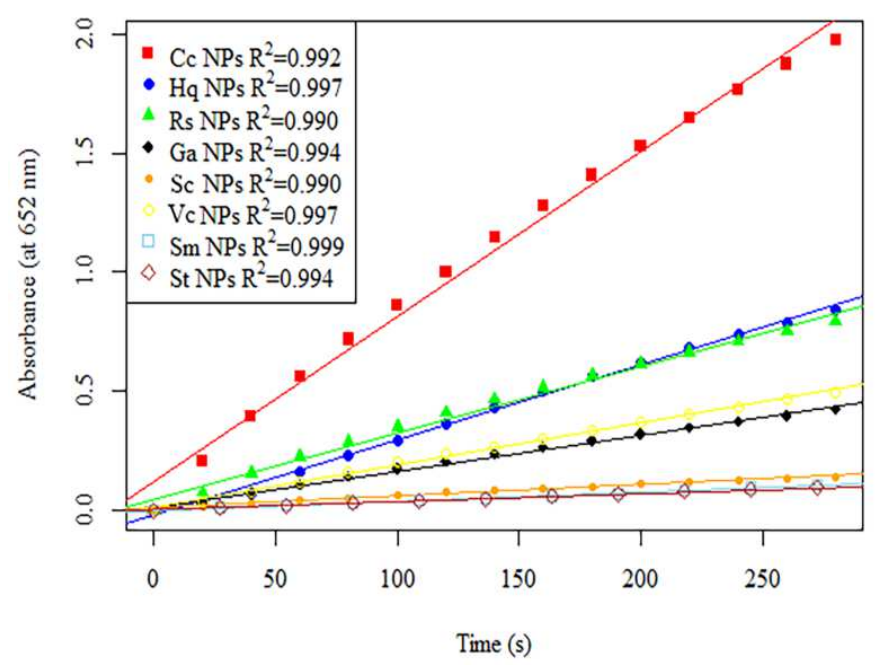

Figure 7: The initial linear part of the reaction-time curves of TMB colorimetric reaction catalyzed by colloidal gold nanoenzyme prepared with eight different reducing agents, such as Cc, Hq, Rs, Vc, Ga, Sc, Sm and St.

The IR spectra of the colloidal gold prepared by Vc, Sc, Sm and St reduction were analysed (Figure 8b), and the results showed that there was a $-\mathrm{OH}$ stretching vibration peak at $3449 \mathrm{~cm}^{-1}$. The results indicate that the peak intensity of Sc is the lowest, but the peak intensity of Sm is very strong. The reason is that it may contain water molecules. The wavenumbers $2984 \mathrm{~cm}^{-1}$ and $2980 \mathrm{~cm}^{-1}$ belong to C-H stretching vibration peak on saturated carbon chain, $1750-1680 \mathrm{~cm}^{-1}$ belong to carbonyl stretching vibration peak, $1422 \mathrm{~cm}^{-1}, 1314 \mathrm{~cm}^{-1}$ and $1039 \mathrm{~cm}^{-1}$ mainly belong to $\mathrm{C}-\mathrm{H}$ in-plane bending vibration and C-C single skeleton vibration. However, in the process of preparing colloidal gold, the ring of Vc is opened and 
the double bond is reduced, resulting in the two kinds of infrared characteristic peaks not appearing. To further study the effect of the amount and position of carboxyl and hydroxyl groups in linear chain organic acids on the enzyme activity, three linear chain organic acids with insignificant structural differences (tartrate, citrate, malate) were used as reductants to prepare colloidal gold, and the enzymatic activity of colloidal gold was examined. The detection results are shown in Figure 8c, with the order of Sodium citrate $>$ Sodium malate $>$ Sodium tartrate, Citric acid is tricarboxylic acid, while malic acid and tartaric acid are dicarboxylic acids. Malic acid has one fewer alcohol hydroxyl group than tartaric acid. Under conditions with the same carbon skeleton, tartaric acid has one more hydroxyl group than malic acid, which eventually leads to the hydroxyl radicals generated from hydrogen peroxide adsorbed on the surface of colloidal gold being more easily eliminated. Malic acid has one fewer carboxyl group than citric acid. Although they are both @ - hydroxyl group, due to bond angle differences, citric acid is less active in hydroxyl groups than malic acid, ultimately leading to the generation of hydroxyl radicals that better bind to TMB.
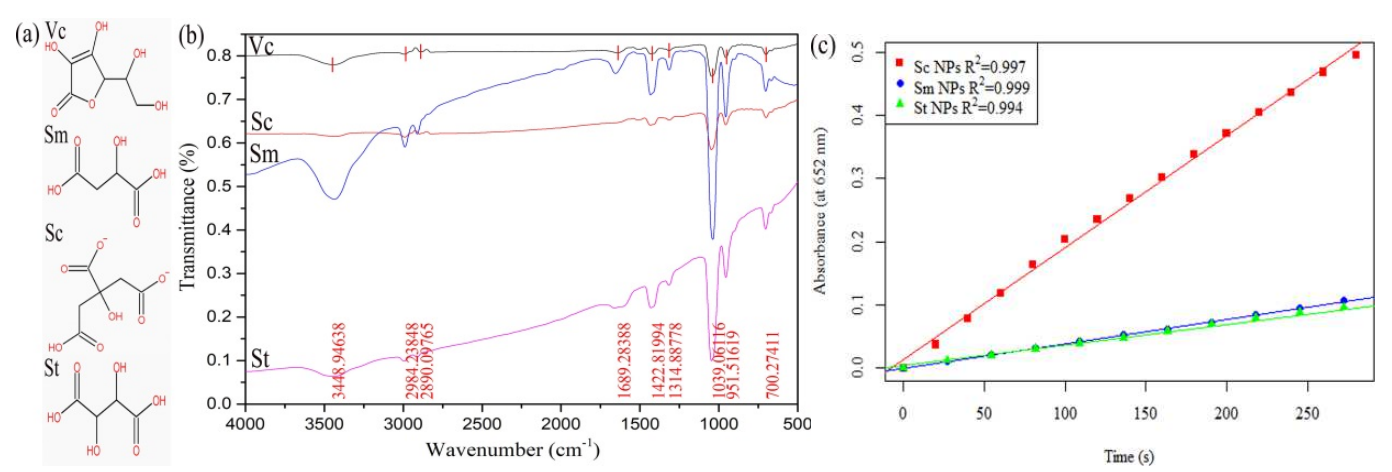

Figure 8: (a) The molecular structure of $\mathrm{Vc}, \mathrm{Sc}, \mathrm{Sm}$ and $\mathrm{St}$ and (b) the infrared spectrum of the reduction to prepare colloidal gold (c) Part of Figure 7.

The colloidal gold prepared by four kinds of phenol reduction method were analyzed by FTIR (Figure 9b), It is not difficult to find that there is a broad peak at $3417 \mathrm{~cm}^{-1}$, which can be attributed to the stretching vibration peak of water molecules, C-H stretching vibration peak at $2991 \mathrm{~cm}^{-1}$ and $2900 \mathrm{~cm}^{-1}$, the quinone carbonyl stretching vibration peak at $1667 \mathrm{~cm}^{-1}$ and benzene absorption peak at $1426 \mathrm{~cm}^{-1}$ and $1314 \mathrm{~cm}^{-1}$. However, no characteristic peaks of four phenols were found in the fingerprint area, indicating that all phenols participated in the reduction and stabilization of colloidal gold. Experimental studies on Cc, Rs, Hq were carried out mainly to comparatively analyse the differences in the nanozyme activity of prepared colloidal gold from the perspective of isomers. Due to their different molecular structures, the ease of their redox reactions varies. The hydroxyl group on the benzene ring belongs to electron withdrawing group, but because its conjugation effect is greater than its electron withdrawing ability, the hydroxyl group will eventually act as electron donating group. The two 
hydroxyl groups on the phenyl ring differ in position and therefore in the distribution of charge density, which leads to differences in their degree of redox. Among the three isomers, when the two hydroxyl positions are in the para position of benzene ring, the charge density is the highest, followed by the ortho position and the meta position. However, because the phenolic hydroxyl group of catechol is in the ortho position, their electron cloud densities influence each other, which greatly enhances the charge effect. Finally, the colloidal gold prepared by catechol reduction method had the highest surface activity, followed by hydroquinone and resorcinol.
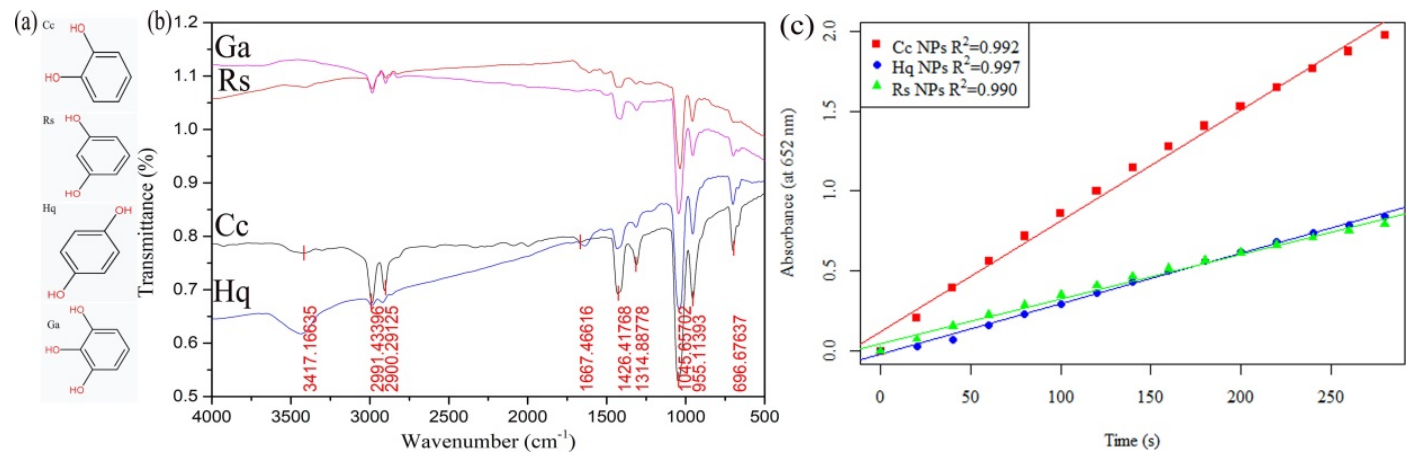

Figure 9: (a) The molecular structure of $\mathrm{Cc}, \mathrm{Hq}, \mathrm{Rs}$, Ga and (b) the infrared spectrum of the reduction to prepare colloidal gold (c) Part of Figure 7.

\section{Conclusion}

Colloidal gold with similar particle size was prepared by optimization processes, and the enzyme activity of eight different surface-modified colloidal gold was verified. The results showed that the enzyme activity of colloidal gold reduced by benzene ring is higher than that of colloidal gold enzyme reduced by linear chain. The effects of isomers, number, and location of functional groups on the enzymatic activity of colloidal gold prepared with three different hydroquinones and three kinds of linear chain organic acids as reductants are discussed separately. Hydroquinone affects the reactivity of the colloidal gold surface, resulting in a different number of hydroxyl radicals producted, while linear chain organic acids affect the reaction efficiency of hydroxyl radical and TMB, resulting in the difference in enzyme activity. 
- Ethics approval and consent to participate

Not applicable

- Consent for publication

Not applicable

- Availability of data and materials

The data and materials that support the findings of this study are available from the corresponding author upon reasonable request.

- Competing interests

The authors declare that they have no competing interests.

- Funding

This article was supported by National Natural Science Foundation of China (No. 32060224).

- Authors' contributions

Feng Shi provided the experimental platform, Junjun Cao carried out the Conception and design of the research, Jie Zhang participated in the Acquisition of data. Ning Yuan carried out the Analysis and interpretation of data. Junjun Cao and Yixiao Sun participated in the design of the study and performed the statistical analysis. Junjun Cao and Zhihua Xu conceived of the study, and participated in its design and coordination and helped to draft the manuscript and revision of manuscript for important intellectual content. All authors read and approved the final manuscript.

- Acknowledgements

Not applicable. 


\section{References:}

[1] Zhang RF, Fan KL, Yan XY (2020) Nanozymes: created by learning from nature[J].Science China Life Sciences 63:1183-1200

[2] Breaker RR (1997) DNA enzymes. Nat. Biotechnol 15:427-431

[3] Bornscheuer UT, Huisman GW, Kazlauskas RJ, Lutz S, Moore JC,Robins K (2012) Engineering the third wave of biocatalysis. Nature 485:185-194

[4] Gurung N, Ray S, Bose S, Rai V (2013) A broader view: microbial enzymes and their relevance in industries, medicine, and beyond. BioMed Res. Int. 2013:1-18

[5] Zhou YB, Liu BW, Yang RH, Liu JW (2017) Filling in the Gaps between Nanozymes and Enzymes: Challenges and Opportunities. Bioconjug Chem 28:2903-2909

[6] Yan XY (2018) Nanozyme: a new type of artificial enzyme. Prog.Biochem. Biophys 45:101-104

[7] Kirby AJ (1994) Enzyme mimics. Angew. Chem., Int. Ed. Engl 33:551-553

[8] Gao L, Zhuang J, Nie L, Zhang J et al (2007) Intrinsic peroxidase-like activity of ferromagnetic nanoparticles. Nature Nanotechnology 2:577-583

[9] Jiang B, Fang L, Wu KM, Yan XY, Fan KL (2020) Ferritins as natural and artificial nanozymes for theranostics. Theranostics 10:687-706

[10] Wu JX, Wang XY, Wang Q et al (2013) Nanomaterials with enzyme-like characteristics (nanozymes): next-generation artificial enzymes. Chemical Society Reviews 42:6060-6093

[11] Yao J, Cheng Y, Zhou M et al (2018) ROS scavenging $\mathrm{Mn}_{3} \mathrm{O}_{4}$ nanozymes for in vivo anti-inflammation. Chem Sci 9:2927-2933

[12] Lin SC, Wei H (2019) Design of high performance nanozymes: a single-atom strategy. Sci China Life Sci $62: 710-712$

[13] Chang CC, Chen CP, Wu TH, et al (2019) Gold nanoparticle-based colorimetric strategies for chemical and biological sensing applications. Nanomaterials 9:861-885

[14] Fu Y, Zhang HX, Dai SD et al (2015) Glutathione-stabilized palladium nanozyme for colorimetric assay of silver(I) ions. Analyst 140:6676-6683

[15] Ray B, Singh S, Mitra K et al (2017) Colorimetric detection of hydrogen peroxide and glucose using brominated graphene. Analytical Methods 9:6675-6681

[16] Zhou YB, Liu BW, Yang RH, Liu JW (2017) Filling in the gaps between nanozymes and enzymes: challenges and opportunities. Bioconjugate Chem 28:2903-2909

[17] Wu JX, Wang XY, Wang Q et al (2019) Nanomaterials with enzyme-like characteristics (nanozymes): next-generation artificial enzymes (II). Chem Soc Rev 48:1004-1076 
[18] Asati A, Santra S, Kaittanis C et al (2009) Oxidase-Like Activity of Polymer-Coated Cerium Oxide Nanoparticles. Angew Chem Int Ed 48:2308-2312

[19] Ahmed S, Annu, Ikram S et al (2016) Biosynthesis of gold nanoparticles:a green approach. J Photochem Photobiol B, Biol 161:141-153

[20] Peng FF, Zhang Y, Gu N (2008) Size-dependent peroxidase-like catalytic activity of $\mathrm{Fe}_{3} \mathrm{O}_{4}$ nanoparticles. Chinese Chemical Letters 19:730-736

[21] Liu B, Liu J (2017) Surface modification of nanozymes. Nano Research 10:1125-1148

[22] Shi J, Yin TX, Shen WG (2019) Effect of Surface Modification on the Peroxidase-like Behaviors of Carbon Dots[J]. Colloids and surfaces B: Biointerfaces 178:163-169

[23] Li JN, Liu WQ, Wu XC et al (2015) Mechanism of pH-switchable peroxidase and catalase-like activities of gold, silver, platinum and palladium. Biomaterials 48:37-44

[24] Luo WJ, Zhu CF, Su S et al (2010) Self-catalyzed, self-limiting growth of glucose oxidase-mimicking gold nanoparticles. Acs Nano 4:451-7458

[25] JV Y, Li BX, Cao R (2010) Positively-charged gold nanoparticles as peroxidase mimic and their application in hydrogen peroxide and glucose detection. Chem Commun 46:8017-8019

[26] Alkilany AM, Yaseen A, Kailani MH (2015) Synthesis of Monodispersed Gold Nanoparticles with Exceptional Colloidal Stability with Grafted Polyethylene Glycol-g-polyvinyl Alcohol. Journal of Nanomaterials, 2015:1-9

[27] Jiang B, Duan DM et al (2018) Standardized assays for determining the catalytic activity and kinetics of peroxidase-like nanozymes. Nature Protocols 13:1506-1520

[28] Lee YH, Park TG (2011) Facile Fabrication of Branched Gold Nanoparticles by Reductive Hydroxyphenol Derivatives. Langmuir 27:2965-2971

[29] Luo XL, Xie X, Meng YC, Sun TL et al (2019) Ligands dissociation induced gold nanoparticles aggregation for colorimetric $\mathrm{Al}^{3+}$ detection. Anal Chim Acta 1087:76-85

[30] Ortega AB, Carrasco MLA, Méndez Otero MM et al (2014) Nonlocal nonlinear refractive index of gold nanoparticles synthesized by ascorbic acid reduction: Comparison of fitting models. Journal of Modern Optics, 61:S68-S73

[31] Liu N, Wang K, Gao YY et al (2017) Tartrate as a substitute of citrate to prepare gold colloids from chloroauric acid[J]. Colloids and Surfaces A Physicochemical and Engineering Aspects 535:251-256

[32] Turkevich J, Garton G, Stevenson PC (1954) The color of colloidal gold. J. Colloid 9:26-35

[33] Rastogi L, Dash K, Ballal A (2017) Selective colorimetric/visual detection of $\mathrm{Al}^{3+}$ in ground water using ascorbic acid capped gold nanoparticles. Sensors \& Actuators B Chemical 248, 124-132 
[34] Perez-Benito JF (2004) Iron(iii)-hydrogen peroxide reaction: Kinetic evidence of a hydroxyl-mediated chain mechanism. J Phys Chem A 108:4853-4858

[35] Cui H, Zhang ZF, Shi MJ et al (2005) Light Emission of Gold Nanoparticles Induced by the Reaction of Bis(2,4,6-trichlorophenyl) Oxalate and Hydrogen Peroxide. Analytical Chemistry 77:6402-6406

[36] Li J, Wu J, Zhang X et al (2011) Controllable Synthesis of Stable Urchin-like Gold Nanoparticles Using Hydroquinone to Tune the Reactivity of Gold Chloride. Journal of Physical Chemistry C 115:3630-3637 
Figures

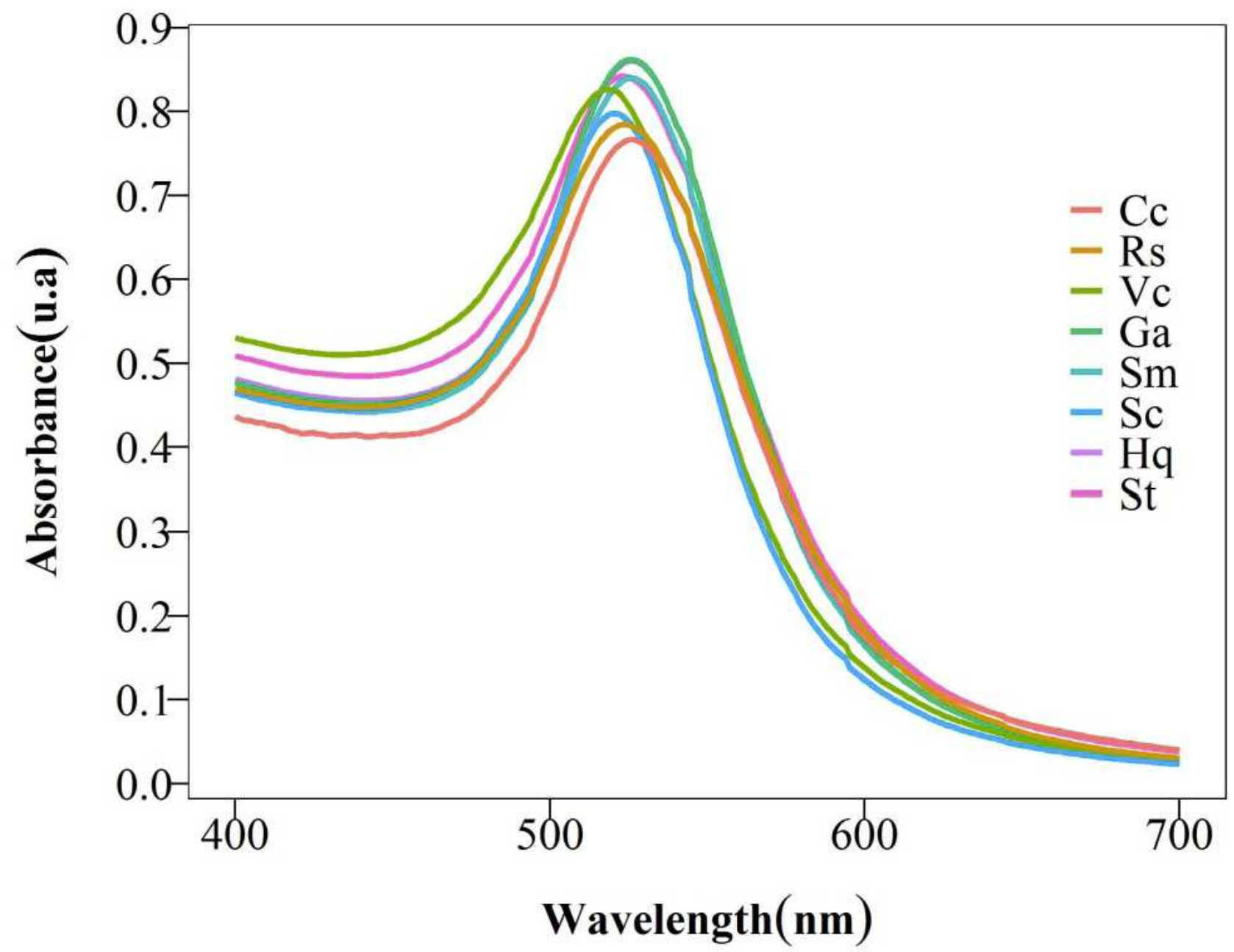

Figure 1

Visible light (400-700 nm) absorption spectra of colloidal gold $(\lambda / \mathrm{nm})$ 

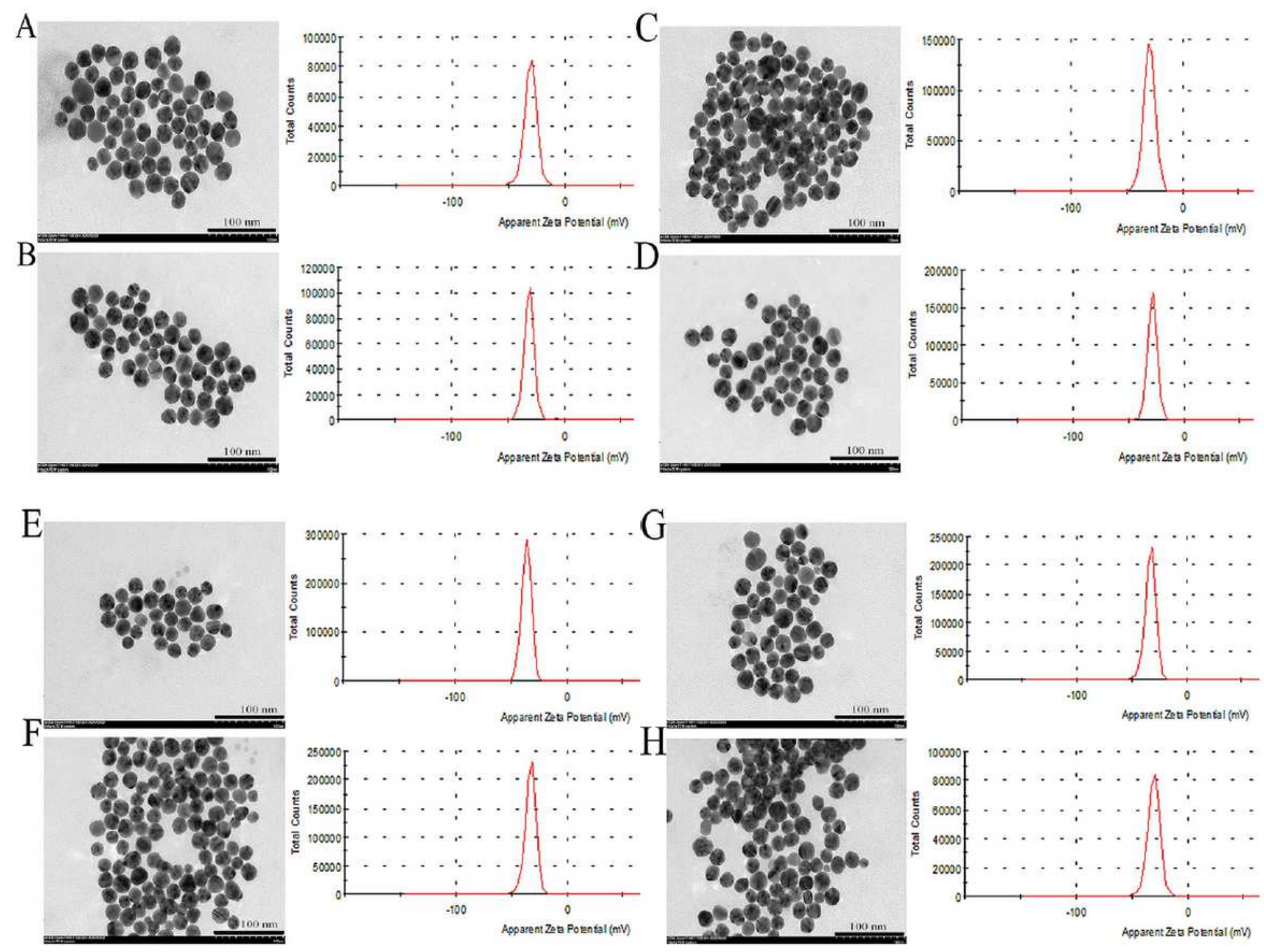

Figure 2

The particle size distribution, TEM and zeta potential of colloidal gold prepared by reduction with $\operatorname{Cc}(A)$, $\mathrm{Hq}(\mathrm{B}), \mathrm{Rs}(\mathrm{C}), \mathrm{Vc}(\mathrm{D}), \mathrm{Ga}(\mathrm{E}), \mathrm{Sc}(\mathrm{F}), \mathrm{Sm}(\mathrm{G})$ and $\mathrm{St}(\mathrm{H})$. 
(a)

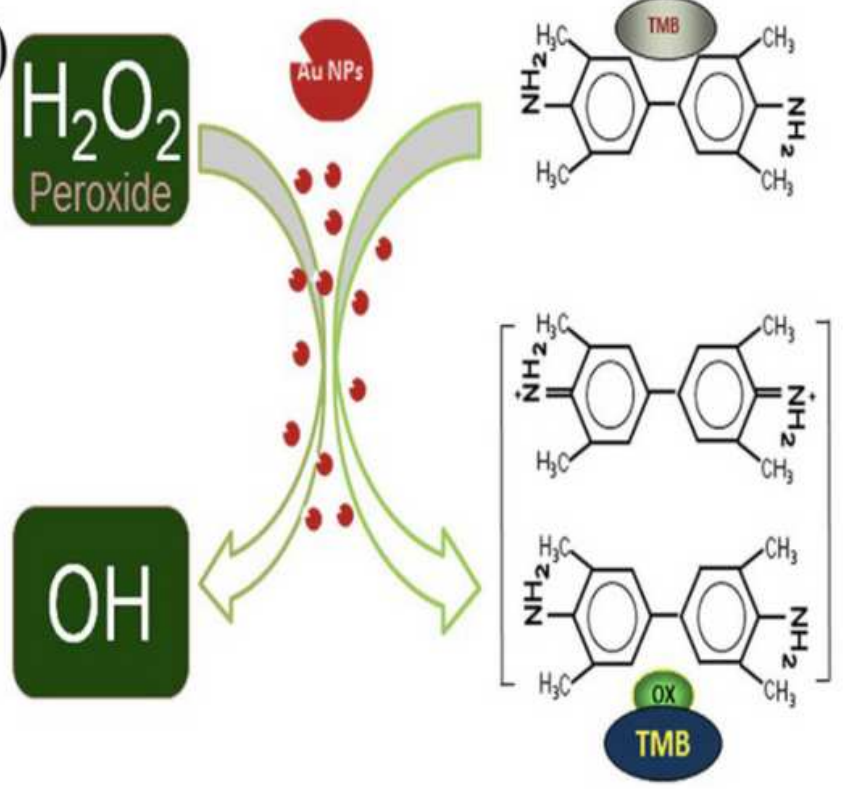

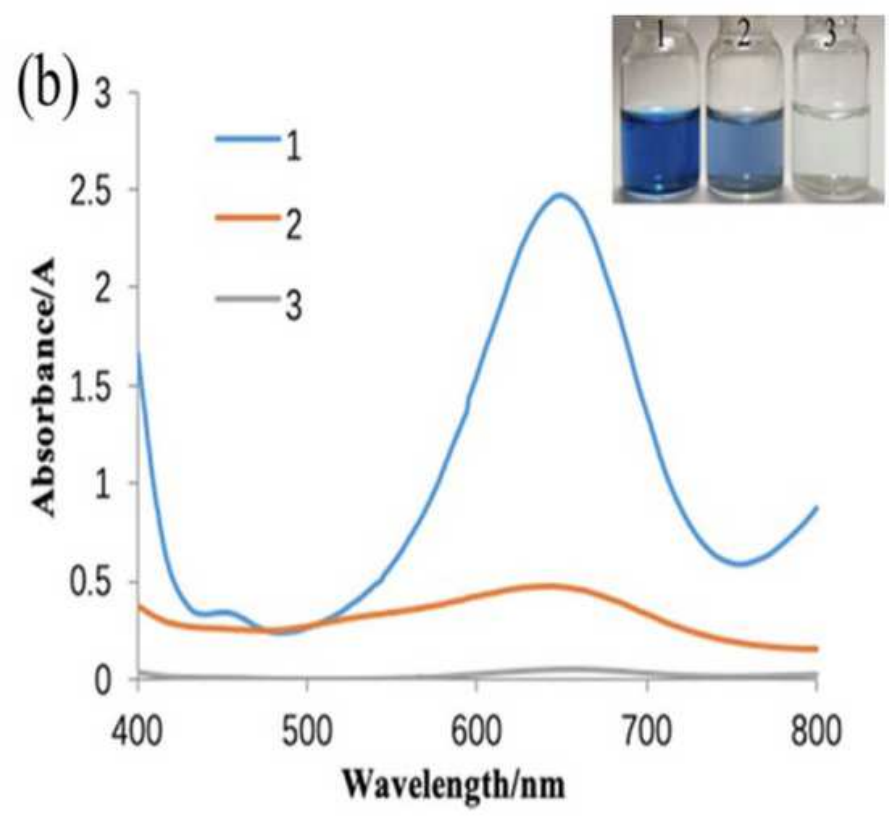

Figure 3

(a) Mechanism of peroxidase activity of the colloid gold (b)UV spectrogram and photo of nanoenzyme activity verification

Study on the conditions of simulated enzyme test

\begin{tabular}{|c|c|c|c|c|c|c|c|c|c|}
\hline & & & & & & & & Tem & $m$ \\
\hline 0.74 & 0.94 & 0.81 & 0.73 & 0.92 & 0.75 & 0.33 & 0.51 & 25 & 60 \\
\hline 0.93 & 0.90 & 1.74 & 2.07 & 1.98 & 1.57 & 0.79 & 0.92 & & \\
\hline 1.03 & 1.93 & 2.36 & 2.62 & 278 & 280 & 1.33 & 2.83 & & \\
\hline 1.07 & 1.60 & 2.37 & 291 & 288 & 241 & 2.73 & 2.87 & 05 & \\
\hline 0.97 & 1.76 & 2.28 & 2.70 & 275 & 281 & 1.74 & 1.65 & & \\
\hline 0.74 & 1.00 & 1.17 & 1.38 & 0.97 & 0.94 & 0.42 & 0.59 & & \\
\hline 0.60 & 1.04 & 0.76 & 0.68 & 0.63 & 0.44 & 0.29 & 0.42 & & \\
\hline 0.74 & 0.86 & 0.69 & 0.60 & 0.59 & 0.42 & 0.34 & 0.47 & & \\
\hline
\end{tabular}


Figure 4

Orthogonal analysis of $\mathrm{pH}$ and temperature of colloidal gold prepared by Sc reduction method
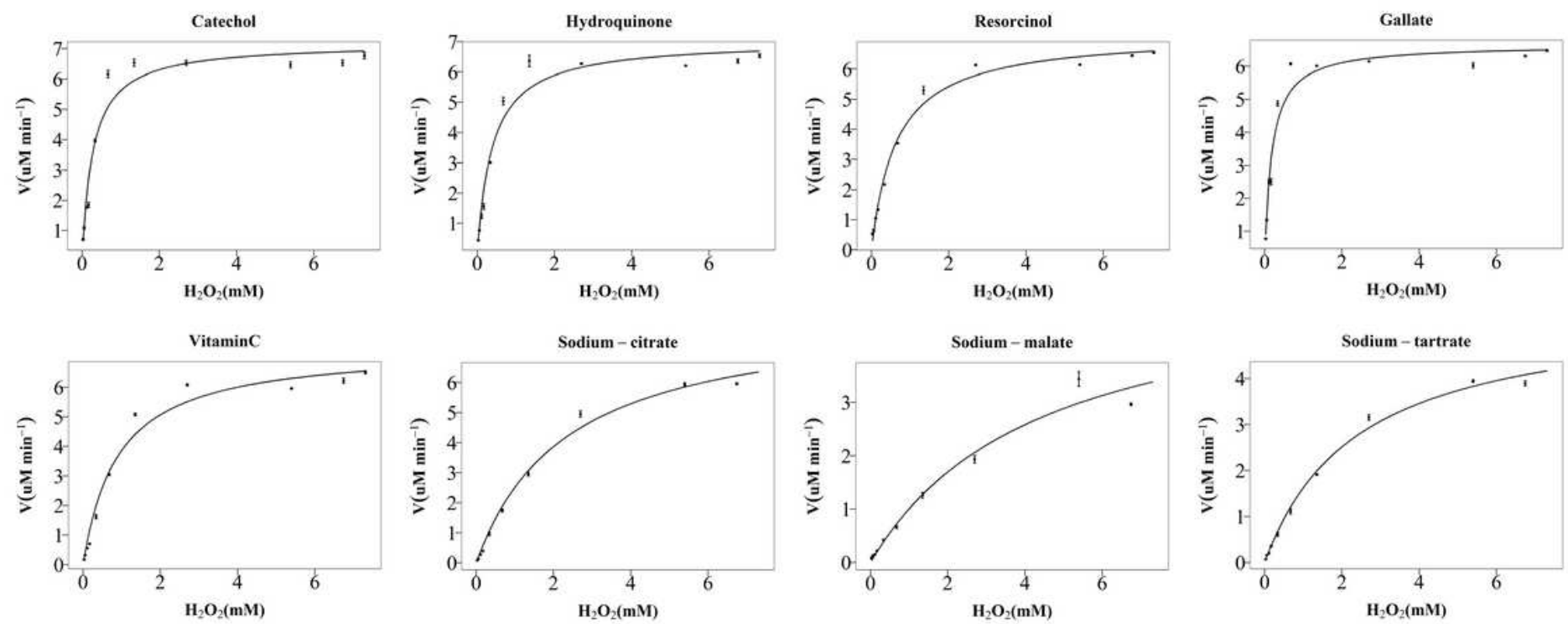

\section{Figure 5}

Michaelis-Menten curves for nanozymes prepared with eight different reducing agents, such as $\mathrm{Cc}, \mathrm{Hq}$, Rs, Vc, Ga, Sc, Sm and St. The concentration of TMB used was $1 \%$, and the $\mathrm{H} 2 \mathrm{O} 2$ concentration varied from 0 to nearly $30 \%$. Error bars shown represent the s.e. derived from three independent experiments.
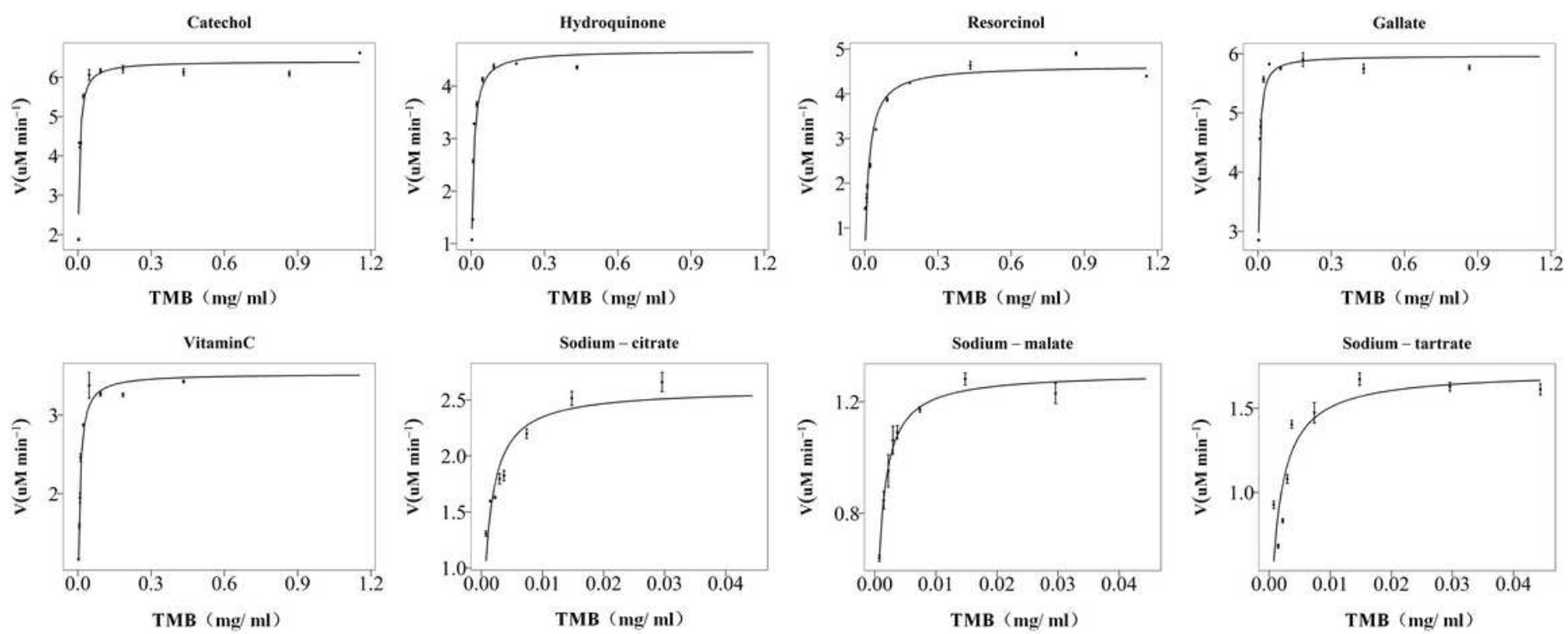

\section{Figure 6}

Michaelis-Menten curves for nanozymes prepared with eight different reducing agents, such as $\mathrm{Cc}, \mathrm{Hq}$, Rs, Vc, Ga, Sc, Sm and St. The concentration of $\mathrm{H} 2 \mathrm{O} 2$ used was $30 \%$, and the TMB concentration varied from 0 to nearly $1 \%$. Error bars shown represent the s.e. derived from three independent experiments. 


\section{Peroxidase-like activity}

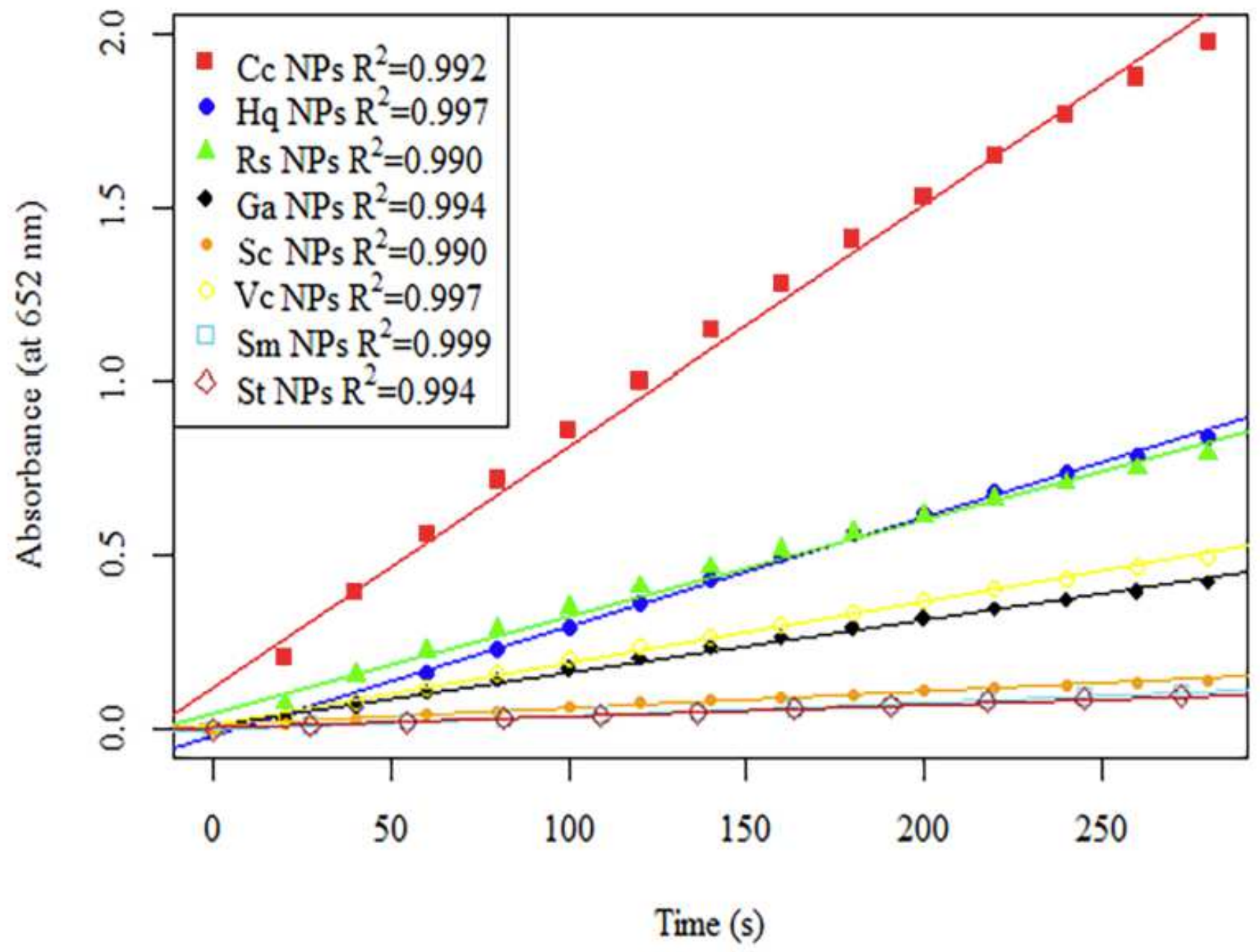

Figure 7

The initial linear part of the reaction-time curves of TMB colorimetric reaction catalyzed by colloidal gold nanoenzyme prepared with eight different reducing agents, such as $\mathrm{Cc}, \mathrm{Hq}, \mathrm{Rs}, \mathrm{Vc}, \mathrm{Ga}, \mathrm{Sc}, \mathrm{Sm}$ and St.

(a) $\mathrm{V}$

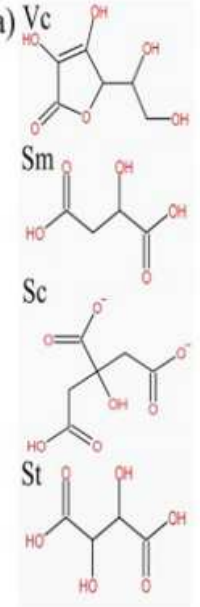

(b)

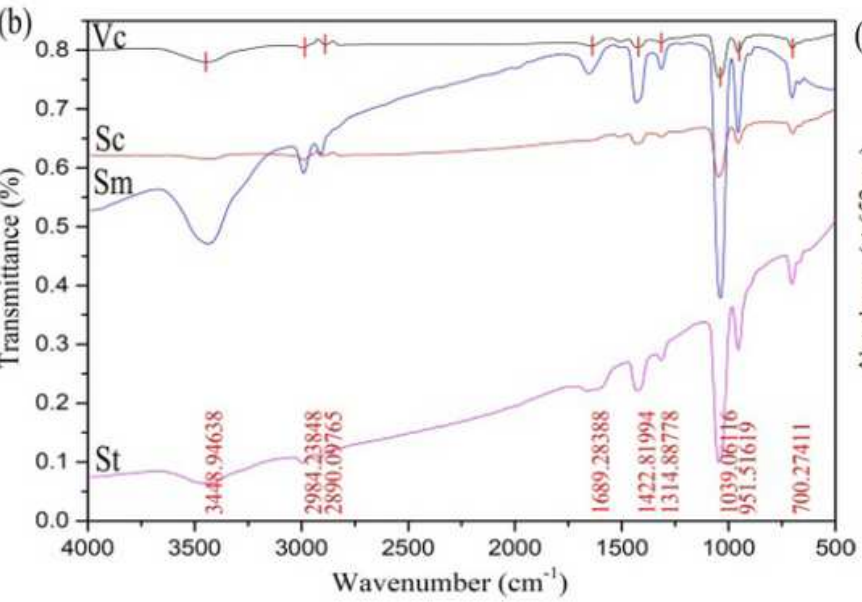

(c) : $: \mathrm{Sc} \mathrm{NPs} \mathrm{R}^{2}=0.997$

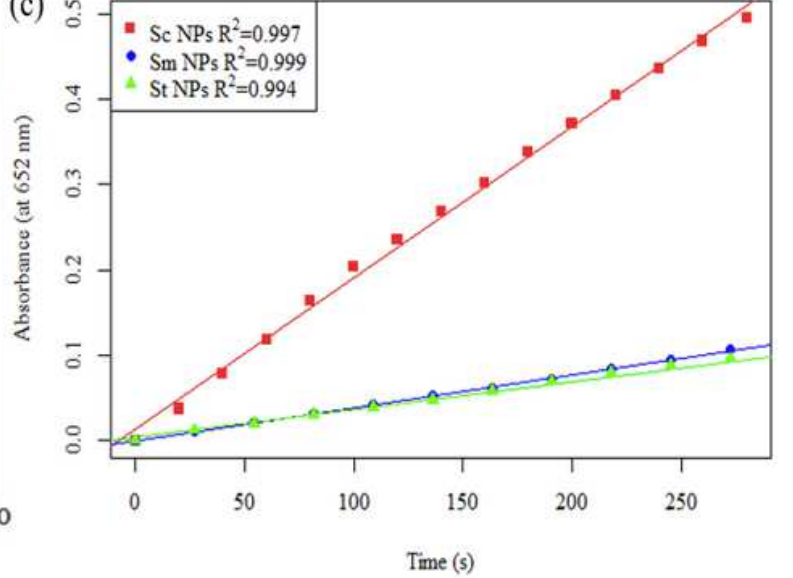


Figure 8

(a) The molecular structure of $\mathrm{Vc}, \mathrm{Sc}, \mathrm{Sm}$ and St and (b) the infrared spectrum of the reduction to prepare colloidal gold (c) Part of Figure 7.

(a) ce

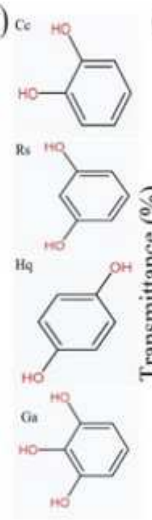

(b) $1.2 \mathrm{Ga}$
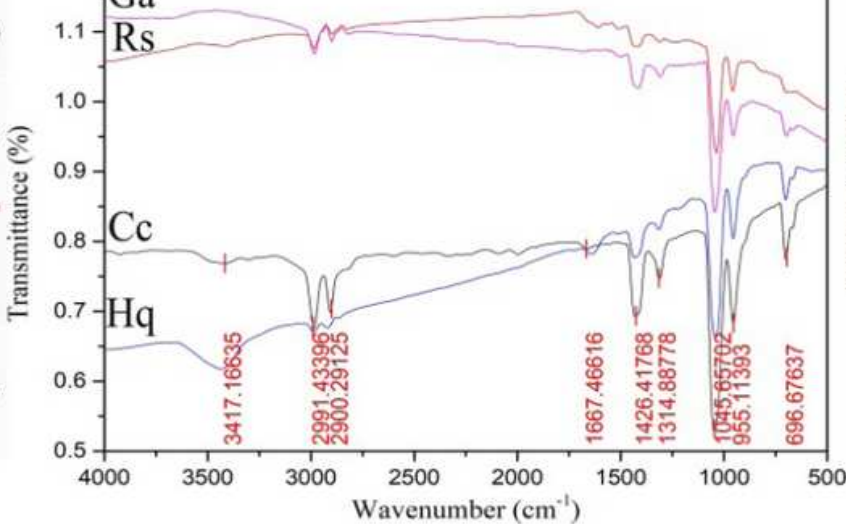

(c) $\stackrel{\text { i }}{2}$

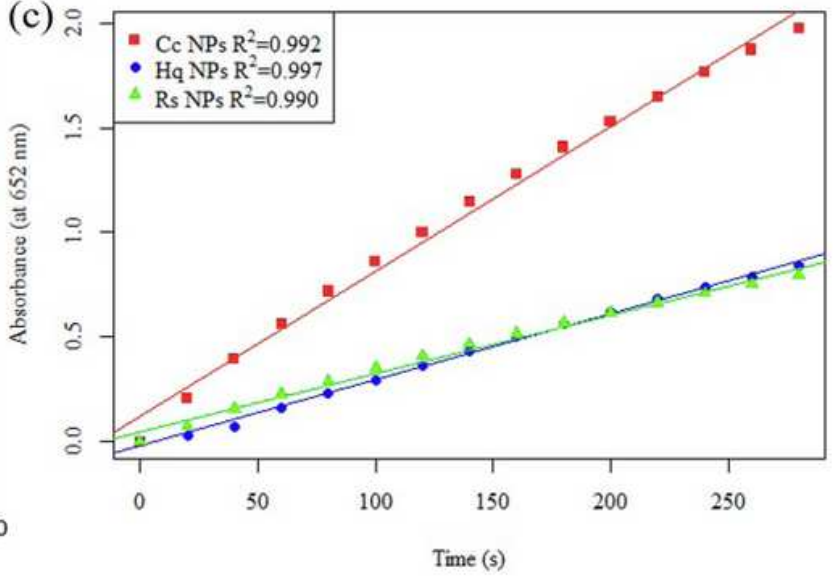

Figure 9

(a) The molecular structure of $\mathrm{Cc}, \mathrm{Hq}, \mathrm{Rs}, \mathrm{Ga}$ and (b) the infrared spectrum of the reduction to prepare colloidal gold (c) Part of Figure 7.

\section{Supplementary Files}

This is a list of supplementary files associated with this preprint. Click to download.

- GraphicalAbstract.tif 